\section{Endovascular Treatment of Acute Vertebrobasilar Artery Occlusion: One Institution's Experience}

\section{Abstract}

Background: Acute vertebrobasilar artery occlusion (VBAO) is associated with high mortality and disability. Because of the poor efficacy of intravenous thrombolysis (IVT), greater attention has been directed to endovascular treatment (ET). Some randomized trials have demonstrated the effectiveness and safety of ET for anterior circulation infarction caused by proximal intracerebral artery occlusion. The improvement of these trials was attributed to the wider application of the Solitaire stent retriever. Stent retrievers work by temporarily deploying a stent that captures the thrombus and at the same time instantly restores blood flow. However, very few trials have addressed the effectiveness of ET for vertebrobasilar occlusion.

Methods: Between 2011 and 2015, our study included 14 patients who received ET for ischemic stroke caused by acute VBAO in our department. Clinical, imaging, and angiographic data were collected. Successful reperfusion was defined as Thrombolysis in Cerebral Infarction ( $\mathrm{TICl}$ ) grade $\geq 2 \mathrm{~b}$. The modified Rankin scale (mRS) score was used to measure outcome.

Results: The median patient age, NIHSS score on admission, Glasgow coma score (GCS), and onset-to-treatment interval were 61.5 (range 43-77), 24.0 (range 6-30), 8.5 (range 4-15), and 561.5 min (range 120-1080), respectively. Recanalization was successful ( $\mathrm{TICl}$ grade $\geq 2 \mathrm{~b}$ ) in 12 of 14 patients (85.7\%). One patient $(7.1 \%)$ suffered a symptomatic intracerebral hemorrhage. At 3 months, 35.7\% (5/14) overall had good and moderate outcome (mRS $\leq 3$ ); $37.5 \%$ of patients treated with an SR procedure as the initial ET and $16.7 \%$ of patients treated with IAT as the initial ET had good outcome ( $m R S \leq 2)$.

Conclusions: ET for acute VBAO is associated with a high successful recanalization rate. Among ETs, the SR procedure may be superior to IAT at improving clinical outcome. An SR procedure rather than IAT should be the initial modality in patients with acute vertebrobasilar occlusion who undergo endovascular treatment. Careful patient selection may be the key to improving good outcome rate.

Keywords: Acute vertebrobasilar occlusion; Ischemic stroke; Endovascular treatment; Stent retriever

\author{
Weibiao Lu ${ }^{1 \#}$, \\ Hongyu Qiao"\#, \\ Min Guan², \\ Zhilin Xiong ${ }^{1}$, \\ Wenxian $\mathrm{Li}^{1}$, \\ Zhen Jing ${ }^{1}$ and \\ Li'an Huang ${ }^{1,3}$
}

1 The First Affiliated Hospital, Department of Neurology, Jinan University, Guangzhou, China;

2 The First Affiliated Hospital, Department of Interventional Neuroradiology, Jinan University, Guangzhou, China

3 Dr Li'an Huang, Department of Neurology, The First Affiliated Hospital, Jinan University, Guangzhou, Guangdong

\# These authors contributed equally to this work.

\section{Corresponding author: Dr Li'an Huang}

Department of Neurology, The First Affiliated Hospital, Jinan University, Guangzhou, Guangdong 510632

\section{huanglian1306@126.com}

Citation: Weibiao Lu, Qiao H, Guan M, et al. Endovascular Treatment of Acute Vertebrobasilar Artery Occlusion: One Institution's Experience . J Biomedical Sci. 2016, 4:2.

\section{Introduction}

Acute vertebrobasilar artery occlusion (VBAO) is associated with high mortality and disability [1]. The use of intravenous thrombolysis within 3-4.5 h of acute ischemic stroke is still the standard treatment [2]. Because of the narrow therapeutic window and the poor efficacy of the intravenous thrombolysis (IVT) $[3,4]$, greater attention has been directed to endovascular treatments ETs (including intra-arterial thrombolysis, mechanical thrombectomy, and stent implantation). ET has 2 advantages: firstly, it increases the percentage of candidates for recanalization treatment among patients with ischemic stroke and secondly, 
it increases the rate recanalization success [5]. The MR CLEAN, EXTEND-IA, and ESCAPE randomized trials demonstrated that ET is effective and safe in patients with acute ischemic stroke caused by proximal intracerebral occlusion of the anterior circulation [6-8]. However, the evidence of its superiority over IVT in vertebrobasilar occlusion is insufficient.

We retrospectively studied 14 cases of acute VBAO treated with ET in our hospital from 2011 to 2015 and evaluated the efficacy and safety of endovascular treatment for vertebrobasilar occlusion.

\section{Methods}

\section{Patients}

Candidates for this study were consecutive patients with acute ischemic stroke who received ET for vertebral and/or basilar artery occlusion between 2011 and 2015 in our hospital. The baseline characteristics (Table 1 ) including age, gender, vascular risk factors (hypertension, diabetes mellitus, atherosclerosis, hyperlipidemia, history of tobacco use), and thrombolysis onsetto-treatment time were collected.

\section{Clinical evaluation}

The severity of acute ischemic stroke was evaluated by the National Institutes of Health Stroke Scale (NIHSS) and Glasgow Coma Scale (GCS) scores at the time of hospitalization (Table 1). The NIHSS scores at discharge were also recorded. Clinical evaluation was performed by neurologists.

\section{Diagnostic workup}

Head CTs and/or MRIs were performed to confirm the diagnosis of posterior circulation infarction, and angiography was recommended to locate the occlusion, responsible arteries, collateral flow, and other vascular lesions that may affect patient management.

\section{Cerebral angiography and endovascular treatment}

Patients were taken to the intervention neuroradiology suite. Cerebral angiography was performed under general anesthesia. A $6 \mathrm{Fr}$ femoral introducer was placed into the right femoral artery. After access was obtained, heparin $(70 \mu / \mathrm{kg})$ was given and a $5 \mathrm{~F}$ diagnostic catheter was introduced into the left vertebral artery for angiography, then exchanged for a $6 \mathrm{~F}$ guiding catheter (Neuron; Penumbra, Alameda, CA), permitting the delivery of a microcatheter (ev3, Plymouth, MN, USA) to the location of occlusion or stenosis by the coaxial-catheter technique. The treatment was given via the microcatheter. In the stent retriever procedure, after stent deployment, the deployed stent retriever was pulled back under continuous aspiration with a $50-\mathrm{mL}$ syringe together with the microcatheter into the guiding catheter. Another angiogram was performed to evaluate post treatment flow. The degree of recanalization was assessed using the $\mathrm{TICl}$ scoring system (0: no perfusion; 1 : penetration but no perfusion; 2a: partial perfusion with incomplete distal filling of $<50 \%$ of the expected territory; $2 \mathrm{~b}$ : partial perfusion with incomplete distal filling of $50 \%$ to $99 \%$ of the expected territory;
3: full perfusion with normal filling of the distal branches in a normal hemodynamic fashion) [9]. All patients received a CT scan to detect bleeding within $24 \mathrm{~h}$.

\section{Blood pressure management}

Before ETs, BP should be maintained at or below 185/110 mm $\mathrm{Hg}$. Maintain BP at or below 180/105 mm Hg during reperfusion therapy [2].

\section{Follow up}

Patients were followed up by phone interview or return visit. Outcomes were measured by neurologists using the modified Rankin scale (mRS) score ( $\leq 2$ = good outcome; from $>2$ to $\leq 3=$ moderate outcome; from $4 \leq$ to $\leq 6$ = poor outcome; $>6=$ dead) [10] (Table 1).

\section{Statistical analysis}

Differences in clinical and radiological variables before and after ET were compared between patients with good outcome and patients with poor outcome. Univariate analysis was performed using the Mann-Whitney $U$ test or Fisher exact test, where appropriate (Table 2). Forward stepwise logistic regression including all variables with $\mathrm{P}<0.1$ after univariate analysis was used to determine the predictors of clinical outcome. Statistical analysis was performed using SPSS 19.0 (IBM SPSS Statistics, Armonk, NY).

\section{Results}

The median age, NIHSS score on admission, and GCS score of our 14 patients (12 males, 2 females) were 61.5 (range 43-77), 24.0 (range 6-30), and 8.5 (range 4-15), respectively. In all, $87.5 \%$ of our patients had hypertension, $35.7 \%$ had diabetes and hyperlipidemia, $92.8 \%$ had atherosclerosis, and $57.1 \%$ had a history of smoking. The median time from symptom onset to treatment was $561.5 \mathrm{~min}$ (range 120-1080). The median procedure time was $132 \mathrm{~min}$ (range 70-240). Other demographic and clinical details are shown in Table 1.

Before treatment, vessel occlusion was complete $(\mathrm{TICl}=0)$ in 13 patients and incomplete $(\mathrm{TICl}=2 \mathrm{a})$ in one patient (no. 10). The occlusion locations are listed in Table 1.

The ET procedure for each patient is shown in Table 1. The median number of Solitaire passes and median dose of recombinant tissue plasminogen activator (rt-PA) injected into the thrombus was 3 (range 1-5) and $27.5 \mathrm{mg}$ (range 13-35), respectively.

Recanalization ( $\mathrm{TICl} \geq 2 \mathrm{~b}$ ) was successful in 12 of our 14 patients (85.7\%), with the $\mathrm{TICl}$ score of 3 in 7 patients and $2 \mathrm{~b}$ in 5 . The $\mathrm{TICl}$ scores after an SR procedure (as the initial modality) in 8 patients were 3 in 5 patients (62.5\%) and $2 \mathrm{~b}$ in 2 patients (25.0\%) and, after IAT (as the initial modality) in 6 patients, they were 3 in 2 patients (33.3\%) and $2 \mathrm{~b}$ in 3 patients $(50.0 \%)$.

No procedure-related complications occurred. Postprocedural hemorrhage was radiologically detected by $\mathrm{CT}$ in 3 patients (Nos. 4, 6, and 10). According to the PROACT II criteria [11], postprocedural hemorrhage was asymptomatic in 2 patients (Nos. 4 and 10) and symptomatic in 1 patient (No. 6). Two of 
Table 1.Overview of Patient Data and Clinical Outcome.

\begin{tabular}{|c|c|c|c|c|c|c|c|c|c|c|c|c|c|}
\hline $\begin{array}{l}\text { Case } \\
\text { No. }\end{array}$ & $\begin{array}{l}\text { Age/ } \\
\text { Gender }\end{array}$ & $\begin{array}{l}\text { Vascular } \\
\text { Risk } \\
\text { factors }\end{array}$ & $\begin{array}{l}\text { NIHSS } \\
\text { Before } \\
\text { Treatm- } \\
\text { ent }\end{array}$ & G-CS & IV rt-PA & $\begin{array}{l}\text { Onset to } \\
\text { ET } \\
\text { Time(min) }\end{array}$ & $\begin{array}{l}\text { Side of } \\
\text { occlusion }\end{array}$ & $\begin{array}{l}\text { Endovascular } \\
\text { treatment }\end{array}$ & $\begin{array}{l}\text { Procedure } \\
\text { Time(min) }\end{array}$ & $\begin{array}{l}\text { TICl } \\
\text { Pre/ } \\
\text { post }\end{array}$ & HT & $\begin{array}{c}\text { NIHSS } \\
\text { Discharge }\end{array}$ & $\begin{array}{c}\text { mRS } \\
\text { (3 } \\
\text { months) }\end{array}$ \\
\hline 1 & $77 / \mathrm{M}$ & 2 & 30 & 5 & No & 530 & wBA & IA rt-PA(35mg) & 225 & $0 / 2 b$ & No & 30 & 6 \\
\hline 2 & $71 / \mathrm{F}$ & 4 & 30 & 5 & No & 120 & $\mathrm{dBA}$ & IA rt-PA(18mg) & 165 & $0 / 3$ & No & dead & - \\
\hline 3 & $70 / \mathrm{M}$ & 3 & 22 & 4 & No & 270 & $\mathrm{dBA}$ & IA rt-PA(30mg) & 210 & $0 / 2 a$ & No & - & - \\
\hline 4 & $47 / M$ & 2 & 24 & 11 & No & 810 & $\mathrm{dBA}$ & IA rt-PA(25mg) & 70 & $0 / 2 b$ & Yes & 19 & 6 \\
\hline 5 & $49 / \mathrm{M}$ & 3 & 6 & 13 & No & 330 & dLVA to $p B A$ & IA rt-PA(30mg) & 190 & $0 / 3$ & No & 2 & 2 \\
\hline 6 & $71 / \mathrm{M}$ & 2 & 26 & 5 & No & 780 & $m B A$ & IA rt-PA(25mg) & 210 & $0 / 2 b$ & Yes & 30 & 6 \\
\hline 7 & $57 / M$ & 2 & 9 & 14 & No & 593 & V3-V4 LVA & $\begin{array}{c}\text { Solitaire } A B \rightarrow I A \text { rt- } \\
P A(30 \mathrm{mg})\end{array}$ & 110 & $0 / 3$ & No & 3 & 2 \\
\hline 8 & $62 / \mathrm{M}$ & 2 & 25 & 7 & $73.4 \mathrm{mg}$ & 480 & $\mathrm{pBA}$ & $\begin{array}{c}\text { Solitaire } \\
\mathrm{AB} \rightarrow \mathrm{PTA} \rightarrow \text { Winspan } \\
\text { Stent }\end{array}$ & 97 & $0 / 3$ & No & 17 & 4 \\
\hline 9 & $43 / \mathrm{M}$ & 4 & 27 & 4 & No & 660 & dLVA, dRVA,wBA & $\begin{array}{c}\text { Solitaire } A B \rightarrow I A \text { rt- } \\
P A(13 \mathrm{mg})\end{array}$ & 83 & $0 / 3$ & No & 20 & 5 \\
\hline 10 & $51 / \mathrm{M}$ & 5 & 10 & 15 & No & 960 & $\begin{array}{c}\text { V3-V4 LVA,V4 } \\
\text { RVA }\end{array}$ & $\begin{array}{c}\text { Solitaire } \\
\mathrm{AB} \rightarrow \text { PTA } \rightarrow \text { Winspan } \\
\text { Stent }\end{array}$ & 92 & $2 a / 3$ & Yes & 7 & 2 \\
\hline 11 & $76 / \mathrm{M}$ & 5 & 16 & 10 & No & 215 & BA & Solitaire $A B$ & 75 & $0 / 2 b$ & No & 3 & 2 \\
\hline 12 & $76 / \mathrm{F}$ & 4 & 30 & 6 & No & 660 & dRVA,BA & Solitaire $A B$ & 114 & $0 / 2 b$ & No & dead & - \\
\hline 13 & $52 / \mathrm{M}$ & 2 & 6 & 14 & No & 1080 & dLVA, dRVA, pBA & Solitaire $A B$ & 240 & $0 / 0$ & No & 30 & 6 \\
\hline 14 & $61 / \mathrm{M}$ & 3 & 24 & 12 & $63 \mathrm{mg}$ & 480 & dLVA,pBA & Solitaire $A B$ & 150 & $0 / 3$ & No & 15 & 3 \\
\hline
\end{tabular}

$\mathrm{M}=$ Male, $\mathrm{F}=$ female, GCS=Glasgow coma score, IV rt-PA=intravenous recombinant tissue plasminogen activator, ET=Endovascular treatment, $\mathrm{WBA}=$ whole basilar artery, $\mathrm{dBA}=$ distal basilar artery, $\mathrm{dLVA}=$ distal left vertebral artery, $\mathrm{pBA}=$ proximal basilar artery, $\mathrm{dRVA}=$ distal right vertebral artery, $\mathrm{IA}$ rt-PA(Dose)=intra-arterial recombinant tissue plasminogen activator, PTA=percutaneous transluminal angioplasty, $\mathrm{HT}=$ Hemorrhagic transformation, $\mathrm{TICl}=$ Thrombolysis in Cerebral Infarction, $\mathrm{mRS}=$ modified Rankin Scale.
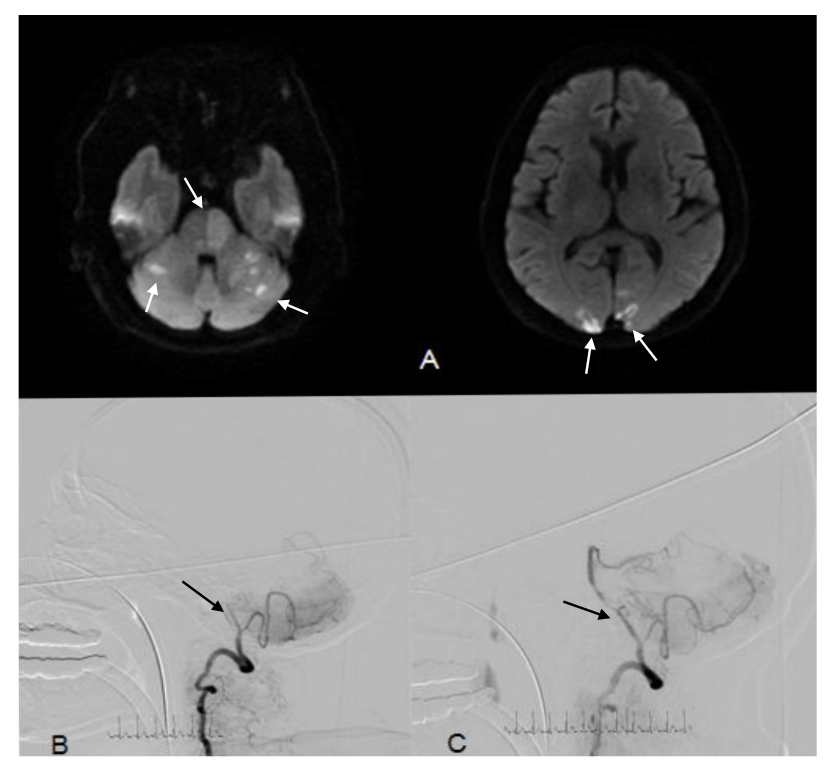

Figure 1 MR of Patient No.6: (A) Infracts can be detected in Bilateral cerebellum and occipital lobe, left pons. DSA of Patient No.6: (B) Left vertebral artery angiogram showing complete occlusion in proximal $1 / 3$ of basilar artery before ET. (C) Recanalization was achieved after $25 \mathrm{mg}$ rt-PA was injected.

these patients with hemorrhage were treated with IAT and one was treated with SR (Figure 1).

NIHSS score improvement (mean 5.4 [range 2-14]) occurred in 8 of our 14 patients (57.1\%) at discharge. Among these 8 patients, 6 were treated with SR and 2 with IAT. The NIHSS score did not change in 3 patients and deteriorated in 1 patient. Three patients died in the hospital. At 3 months, outcome was good in $28.6 \%$ $(4 / 14)$ of patients and moderate in $35.7 \%$ (5/14). Outcome was good in $37.5 \%$ of patients treated with an SR procedure as the initial ET and $16.7 \%$ of patients treated with IAT as the initial ET. The overall mortality rate was $50.0 \%$ (7 of 14 ) at 3 months.

In univariate analysis, 2 clinical factors were identified as predictors of good or moderate clinical outcome: lower NIHSS score on admission ( $p=0.029)$ and higher GCS score ( $p=0.012$; see Table 2). Because of the small sample size, only clinical outcome variables with a probability value $<0.05$ in univariate analysis and other variables identified as predictors of outcome in previous studies were entered into multivariate analysis. In multivariate analysis including age, NIHSS on admission, GCS, symptom onset-to-treatment time, and initial treatment, only higher GCS $(\mathrm{OR}=12.73, \mathrm{p}=0.044)$ was identified as a predictor of good or moderate clinical outcome.

\section{Discussion}

Early recanalization is the primary goal of endovascular treatment and a strong predictor of outcome in endovascular treatment of vertebrobasilar occlusion [10]. In Lindsberg's study and the Basilar Artery International Cooperation Study (BASICS), the rate of recanalization due to IVT was $53 \%$ and $67 \%$, respectively $[12,13]$. Our study demonstrated that ET can achieve recanalization more frequently than IVT in VBAO. 
Table 2.Univariate Analysis of Clinical and Imaging Parameters on Outcome in VBAO.

\begin{tabular}{|c|c|c|c|c|}
\hline & Total(n=14) & $\begin{array}{l}\text { Good or moderate } \\
\text { outcome, } m R S=0-3(n=5)\end{array}$ & Poor outcome, $m R S=4-6(n=9)$ & $\mathbf{P}$ \\
\hline Age & $61.6 \pm 11.9$ & $58.8 \pm 10.7$ & $63.2 \pm 12.8$ & 0.518 \\
\hline Gender(male) & $12(85.7)$ & $4(100)$ & $8(80.0)$ & 0.604 \\
\hline $\begin{array}{l}\text { Initial systolic blood pressure }(\mathrm{mm} \\
\mathrm{Hg})\end{array}$ & $163.2 \pm 22.9$ & $155.8 \pm 18.4$ & $167.3 \pm 25.0$ & 0.522 \\
\hline $\begin{array}{l}\text { Post operation systolic blood } \\
\text { pressure }(\mathrm{mm} \mathrm{Hg})\end{array}$ & $142.1 \pm 23.0$ & $144.4 \pm 23.0$ & $140.9 \pm 30.3$ & 0.689 \\
\hline Diabets & $5(35.7)$ & $2(40.0)$ & $3(33.3)$ & 0.622 \\
\hline Hyperlipidemia & $5(35.7)$ & $3(60.0)$ & $2(22.2)$ & 0.203 \\
\hline History of smoking & $8(57.1)$ & $4(80.0)$ & $4(44.4)$ & 0.238 \\
\hline NIHSS on admission & $20.4(6-30)$ & $10.0(6-24)$ & $24.4(6-30)$ & 0.029 \\
\hline GCS & $9.0(4-15)$ & $12.8(10-15)$ & $6.8(4-11)$ & 0.012 \\
\hline IV t-PA & $2(14.3)$ & $1(20.0)$ & $2(22.2)$ & 0.604 \\
\hline Onset to treatment time & $564.9 \pm 288.5$ & $515.6 \pm 287.0$ & $598.9 \pm 289.9$ & 0.518 \\
\hline Responsible vessel & & & & 0.375 \\
\hline VA & 2 & 2 & 0 & \\
\hline BA & 7 & 1 & 6 & \\
\hline $\mathrm{VA}+\mathrm{BA}$ & 5 & 2 & 3 & \\
\hline Procedure time & $145.1 \pm 60.8$ & $123.4 \pm 46.5$ & $157.1 \pm 66.8$ & 0.364 \\
\hline Initial modality & & & & 0.198 \\
\hline IAT & 6 & 1 & 5 & \\
\hline SR & 8 & 4 & 4 & \\
\hline
\end{tabular}

Data are shown as $\mathrm{n}(\%)$, mean \pm standard deviation or mean( range), IV t-PA=intravenous recombinant tissue plasminogen activator, GCS= Glasgow coma score, $\mathrm{VA}=$ Vertebral artery, $\mathrm{BA}=$ Basilar artery, IAT=Intra-arterial thrombolysis, $\mathrm{SR}=\mathrm{Stent}$ retriever.

Initially, only IAT was used. Gradually, as stent retriever use became more common, IAT was used in conjunction with SR or was replaced by it.

In Lindsberg's systematic analysis and the BASICS study [12,13], the recanalization rates in patients treated with IAT were respectively $65 \%$ and $72 \%$, while the good outcome rates were respectively $24 \%$ and $17.4 \%$. The results of other clinical studies were not as definitive. The efficacies of IAT and IVT seem to be similar. However, if the patients miss the window of therapeutic opportunity for IVT, IAT and other modalities of endovascular should be considered because of the comparatively wider time window [14].

A stent retriever can provide good flow restoration in its role as a temporary intracranial bypass and remove the thrombus [15]. Stent retrievers such as Solitaire were shown to be superior to the first-generation Merci stent retriever and are widely used nowadays [6]. In trials investigating ETs for proximal intracerebral occlusion of anterior circulation (such as MR CLEAN), most of the patients in the ET group were treated with Solitaire stent retrievers. Comparing these trials with previous trials (such as IMS-III), the improvement in results was attributed to the wider application of the Solitaire stent retriever [6-8]. In recent small sample studies of vertebrobasilar occlusion treated by a SR procedure, the good outcome rate ranged from $28.6 \%$ to $50 \%$ [15-18]. In line with previous studies, our study demonstrated that the Solitaire stent retriever may improve clinical outcome in patients with acute VBAO.

In the treatment for acute vertebrobasilar occlusion with underlying atherosclerotic stenosis, angioplasty and stent placement are usually performed following thrombolysis or thrombectomy rather than alone $[19,20]$ (Figure 2). In the study by Shi et al., 9 patients underwent emergency stent placement

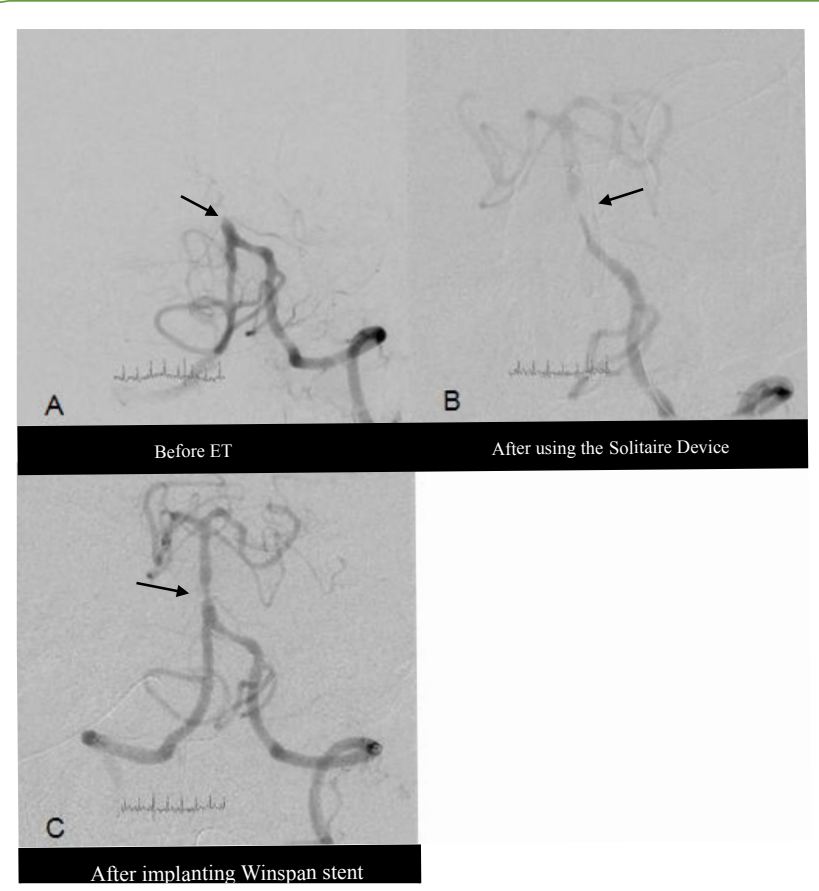

Figure 2 DSA of patient No.8 (A) Left vertebral artery angiogram showing occlusion in the proximal part of basilar artery, the contrast agent flow back to the right vertebral artery, no collateral supply was provided via the posterior communicating arteries. (B) After the Solitaire thrombectomy, the contrast agent can get through, and a $95 \%$ stenosis was detected in the proximal part. (C) After implanting Winspan stent, a significant improvement in the stenosis was achieved.

following inadequate recanalization after thrombolysis [19]. The recanalization rate was $88.9 \%$ and good outcome rate was $44.4 \%$. In the report by Beheme et al., 6 of 7 patients were treated with 
a combination of stent placement and mechanical thrombectomy [21]. Recanalization was achieved in all cases. Outcome at discharge was good in 2 patients and poor in 3 [21]. From the evidence provided by recent studies, we believe that patients with acute vertebrobasilar occlusion based on atherosclerotic stenosis may benefit from angioplasty and stent placement, but stronger evidence from RCTs is still needed.

Factors other than recanalization success can predict the outcome of vertebrobasilar occlusion, such as age, vascular risk factors, NIHSS score on admission, GCS score, the length and location of the occlusion, the symptom-to-treatment time, collateral flow, blood pressure, anesthesia, aspiration via the guide, pretreatment size of infarct [22-29]. In this study, only GCS score could be identified as a predictor of outcome, while other factors identified in previous studies as predictors of outcome (i.e., age, NIHSS score on admission, blood pressure and symptom onsetto-treatment time) did not have great impact on outcome. This reflects a major limitation of our study, which is its small sample size. Though lower GCS was a negative prognosticator in our study, coma should not be a contraindication for ET. In general, most VBAO patients are comatose at the time of treatment [12] In the BASICS study, the good outcome rate of patients with coma, tetraplegia, or locked-in state on admission was reached in $17 \%$ after IAT [13]. Notably, the good outcome rate will be lower if recanalization is not achievable in VBAO patients with severe deficits.

Recent studies have shown disparity between technological improvements in the procedureand ability to select the appropriate patients for the procedure [30]. Recanalization was frequently futile. To decrease the frequency of futile recanalization, patient selection should be emphasized in the future studies. A study on the data from the BASICS demonstrated that the prognosis of patients with acute basilar artery occlusion was poor beyond 9h [31]. Though no window of opportunity for vertebrobasilar recanalization has been established, shorter onset-to-treatment time remains an important inclusion criterion. Multimodal imaging is also important for patient selection in ET for VBAO since the time window is not well established. For example, diffusion weighted image (DWI)- perfusion weighted image (PWI) mismatch can identify the infarct core and ischemic penumbra in the posterior circulation [32]. Recent trials indicated that patients with small infarct core caused by large vessel occlusion can benefit from an SR procedure [8]. Thus, VBAO patients with small infarct core may be candidates for SR procedures.

In our study, 3 patients developed postprocedural intracranial hemorrhage, the main complication of reperfusion therapy [26]. Among them, 1 patient (7.1\%) developed symptomatic postprocedural hemorrhage. In line with the results of previous studies $[12,13,15-18]$, our study demonstrated that endovascular treatment is safe in patients with vertebrobasilar occlusion.

This study has limitations. First, the sample size is so small that it is hard to get revealing answers. Second, its retrospective nature led to non-randomized treatment allocation and incompleteness of data, e.g., accurate puncture-to-recanalization time. However, our study contributes evidence of the efficacy of ET for acute VBAO even though this evidence remains insufficient.

In conclusion, the success rate of endovascular treatment for acute vertebrobasilar occlusion was high, and SR (compared to IAT) may have greater efficacy and safety. The current study demonstrated that SR (as an initial modality) is preferable to IAT in patients with acute vertebrobasilar occlusion who undergo endovascular treatment. Recanalization was frequently futile, and careful patient selection may be the key to improve the good outcome rate. Our results need to be confirmed by further studies. 


\section{References}

1 Delgado Acosta F, Jiménez Gómez E, de Asís Bravo Rodríguez F (2014) Vertebrobasilar recanalization modalities before the placement of stentretrievers: Reopening is not synonymous with good outcome. Radiología (English Edition) 56(1), 44-51.

2 Edward C Jauch, Jeffrey L Saver, Harold P Adams (2013) Guidelines for the Early Management of Patients With Acute Ischemic Stroke; A Stroke Association Guideline for Healthcare Professionals From the American Heart Association/American Guidelines for the Early Management of Patients With Acute Ischemic Stroke. Stroke 44: 870-947.

3 de Los Rios la Rosa F, Khoury J, Kissela BM (2013)Eligibility for intravenous recombinant tissue-type plasminogen activator within a population: the effect of the European Cooperative Acute Stroke Study (ECASS) III trial. Stroke 43: 1591-1595.

4 Rha JH, Saver JL (2007) The impact of recanalization on ischemic stroke outcome: a meta-analysis. Stroke 38: 967-973.

5 Matias-Guiu JA, López-Ibor L (2014) Endovascular treatment for acute ischaemic stroke: in search of evidence. Neurología (English Edition) 29: 65-67.

6 Berkhemer OA, Fransen PS, Beumer D (2015) MR CLEAN investigators. A randomized trial of intraarterial treatment for acute ischemic stroke. N Engl J Med 372: 11-20.

7 Campell BCV, Mitchell PJ, Kleinig TJ (2015) EXTEND-IA investigators. Endovascular therapy for ischemic stroke with perfusion-imaging selection. N Engl J Med Epub ahead of print.

8 Goyal M, Demchuk AM, Menon BK (2015) ESCAPE investigators. Randomized assessment of rapid endovascular treatment of ischemic stroke. N Engl J Med 372: 1019-1030.

9 YUN JS, KWAK HS, HWANG SB, CHUNG GH (2011) Endovascular Management in Patients with Acute Basilar Artery Obstruction:Lowdose Intra-Arterial Urokinase and Mechanical Clot Disruption. Interventional Neuroradiology 17: 435-441.

10 Singer OC, Berkefeld J, Nolte CH (2015) Mechanical recanalization in basilar artery occlusion: The ENDOSTROKE study. Ann Neurol 77: 415-424.

11 Kase CS, Furlan AJ, Wechsler LR (2001) Cerebral hemorrhage after intra-arterial thrombolysis for ischemic stroke: the PROACT II trial. Neurology 57: 1603-1610.

12 Lindsberg PJ, Mattle HP (2006) Therapy of basilar artery occlusion: a systematic analysis comparing intra-arterial and intravenous thrombolysis. Stroke 37: 922-928.

13 BASICS study group. Treatment and outcomes of acute basilar artery occlusion in the Basilar Artery International Cooperation Study(BASICS): a prospective registry study. Lancet Neurol 2009; 8: 724-30.

14 Lindsberg PJ, Sairanen T, Strbian D, Kaste M (2012) Current treatment of basilar artery occlusion. Ann N Y Acad Sci 1268: 35-44.

15 Espinosa de Rueda M, Parrilla G, Zamarro J (2013)Treatment of acute vertebrobasilar occlusion using thrombectomy with stent retrievers: initial experience with 18 patients. AJNR Am J Neuroradiol 34: 1044-1048.

16 Mordasini P, Brekenfeld C, Byrne JV (2013) Technical feasibility and application of mechanical thrombectomy with the Solitaire FR Revascularization Device in acute basilar artery occlusion. AJNR Am J Neuroradiol 34: 159-163.

17 Mourand I, Machi P, Milhaud D (2014) Mechanical thrombectomy with the Solitaire device in acute basilar artery occlusion. J Neurolinterv Surg; 6: 200-204.

18 Baek JM, Yoon W, Kim SK (2014) Acute basilar artery occlusion:outcome of mechanical thrombectomy with Solitaire stent within 8 hours of storke onset.ANJR Am Neuroradiol 35: 989-993.

19 Shi M, Wang S, Zhu H, Feng J, Wu J (2012) Emergent stent placement following intra-arterial thrombolysis for the treatment of acute basilar artery occlusion. J Clin Neurosci 19: 152-154.

20 Wang L, Shi W, Su Z (2015) Endovascular treatment of severe acute basilar artery occlusion. J Clin Neurosci 22: 195-198.

21 Behme D, Weber W, Mpotsaris A (2014) Acute Basilar Artery Occlusion with Underlying High-Grade Basilar Artery Stenosis: Multimodal Endovascular Therapy in a Series of Seven Patients. Clin Neuroradiol 00062-014-0303-9.

22 Möhlenbruch M, Stampfl S, Behrens (2013) Mechanical Thrombectomy with Stent Retrievers in Acute Basilar Artery Occlusion. AJNR Am J Neuroradiol 35: 1-6.

23 G.schulte Altedorneburg, GF Hamann, M Mull (2006) Outcome of Acute Vertebrobasilar Occlusions Treated with Intra-arterial Fibrinolysis in 180 Patients. AJNR Am J Neuroradiol 27: 2042-2047.

24 Arnold M, Nedeltchev K, Schroth G (2004) Clinical and radiological predictors of recanalisation and outcome of 40 patients with acute basilar artery occlusion treated with intra-arterial thrombolysis. J Neurol Neurosurg Psychiatr 75: 857-862.

25 Bang OY, Saver JL, Kim SJ (2011) Collateral flow predicts response to endovascular therapy for acute ischemic stroke. Stroke 42: 693-699.

26 Linfante I, Dabus G, Starosciak A (2014) Predictors of poor outcomes despite successful recanalization in patients with acute ischemic stroke. J Neurointerv Surg 6 Suppl 1: A17-8.

27 Yong M, Diener HC, Kaste M, Mau J (2005) Characteristics of blood pressure profiles as predictors of long-term outcome after acute ischemic stroke. Stroke 36: 2619-2625.

28 Cougo-Pinto PT, Chandra RV, Simonsen CZ, Hirsch JA, Leslie-Mazwi T (2015) Intra-arterial therapy for acute ischemic stroke: a golden age. Curr Treat Options Neuro 17: 360.

29 Gasparotti R, Grassi M, Mardighian D (2009) Perfusion CT in patients with acute ischemic stroke treated with intra-arterial thrombolysis: predictive value of infarct core size on clinical outcome. AJNR Am J Neuroradiol 30(4):7 22-727.

30 Gomis M, Davalos A (2014) Recanalization and Reperfusion Therapies of Acute Ischemic Stroke: What have We Learned, What are the Major Research Questions, and Where are We Headed? Front Neurol Volume 5: Article 226.

31 Vergouwen MDI, Algra A, Pfefferkorn T (2012)Time is brain(stem) in basilar artery occlusion. Stroke 43: 3003-3006.

32 Ostrem JL, Saver JL, Alger JR (2004) Acute basilar artery occlusion: diffusion-perfusion MRI characterization of tissue salvage in patients receiving intra-arterial stroke therapies. Stroke 35: e30-e34. 